\title{
A INFLUÊNCIA DAS ÂNCORAS DE CARREIRA NA SATISFAÇÃO NO TRABALHO PARA OS SERVIDORES DO TRIBUNAL DE CONTAS DO ESTADO DO MARANHÃO
}

\author{
Arlindo Faray Vieira ${ }^{1}$ \\ Sérgio Augusto Pereira Bastos ${ }^{2}$
}

\begin{abstract}
Resumo:
Muito se discute sobre a atuação estatal, sobretudo acerca da qualidade de seus servidores. Dessa forma, este estudo objetiva identificar as principais âncoras de carreira em uma instituição pública, o Tribunal de Contas do Estado do Maranhão, e relacioná-las à satisfação no trabalho. Com esse fim, realiza uma pesquisa descritiva, de abordagem quantitativa, de corte transversal, fazendo uso de um questionário estruturado, validado em pesquisas anteriores. Aborda oito construtos, relativos às âncoras de carreira, como variáveis independentes, a satisfação no trabalho como variável dependente. Os resultados indicaram que as âncoras "segurança e estabilidade" e "competência técnica" são significantes e afetam positivamente a satisfação no trabalho, enquanto a âncora "competência administrativa geral" é inversamente proporcional à satisfação no trabalho. Tais resultados, além da contribuição teórica ao estudo das carreiras públicas, podem contribuir com políticas de gestão de pessoas que, via satisfação no trabalho, produzam serviços de melhor qualidade à sociedade.
\end{abstract}

Palavras-chave: Servidores públicos. Âncoras de carreira. Satisfação no trabalho.

\section{THE INFLUENCE OF CAREER ANCHORS IN JOB SATISFACTION OF SERVERS FROM THE COURT OF ACCOUNTS OF THE STATE OF MARANHÃO}

\section{Abstract:}

There is much discussion about state performance, especially about the quality of its servers. Thus, this study aims to identify the main career anchors in a public institution, the Court of Accounts of the State of Maranhão, and relate them to job satisfaction. For this purpose, a descriptive, quantitative, cross-sectional research was carried out using a structured questionnaire validated in previous researches. Approaches eight constructs, related to career anchors, as the independent variables, and job satisfaction as the dependent variable. The results indicated that the anchors "safety and stability" and "technical competence" are significant and positively affect job satisfaction, while the anchor "general administrative competence" is inversely proportional to job satisfaction. Such results, in addition to the theoretical contribution to the study of public careers, can contribute to the management policies of people who, through job satisfaction, might deliver better quality services to society.

Keywords: Public servers. Career anchors. Job satisfaction.

Artigo recebido em: 13/06/2018 Aprovado em: 28/03/2019. DOI: http://dx.doi.org/10.18764/2178-2865.v23n1p323-338

\footnotetext{
1 Mestre em Administração de Empresas pela FUCAPE Business School, Professor e Coordenador de Curso de Direito da Faculdade UNINASSAU de São Luís e Assistente Jurídico de Licitações e Contratos do Tribunal de Contas do Estado do Maranhão. Endereço: Zoé Cerveira, 637-669 - Alemanha, São Luís - MA. CEP - 65.036-720; Av. Prof. Carlos Cunha, s/n Calhau, São Luís - MA, CEP - 65.076-820. E-mail: arlfaray@hotmail.com

2 Doutor em Administração de Empresas pela Pontifícia Universidade Católica do Rio de Janeiro - PUC-Rio. Professor Associado da FUCAPE Business School . Endereço: Av. Fernando Ferrari, 1.358 - Boa Vista, Vitória - ES, CEP - 29.075505 E-mail: sbastos@fucape.br
} 


\section{INTRODUÇÃO}

As organizações, por serem formadas por pessoas, se encontram em constante estado de metamorfose (SCHEIN, 1996). Ulrich e Ulrich (2011) usaram o termo organização abundante para delinear esse ambiente, onde os sujeitos relacionam suas aspirações e ações correspondentes com 0 fim de criar valores para si mesmos, para a organização, a família ou mesmo para toda a humanidade.

A carreira é construída, sequencialmente, ao longo da história individual das pessoas, em um ambiente organizacional que integra as posições ocupadas, independentemente de qual seja o tipo de trabalho, sob a influência das organizações com que teve contato ou colaborou. (DUTRA, 2010).

Nem mesmo as instituições públicas podem negligenciar a volubilidade das carreiras, e é requerida que a gestão de pessoas, sob a égide estatal, deva observar políticas para gerenciamento desse recurso. (HAYEK, 1987).

Uma nova concepção de administração pública foi cunhada a partir da premissa do modelo gerencial. Emerge daí que houve uma predisposição estatal, iniciada na década de 1970, para que as organizações públicas incluíssem práticas gerenciais mais eficientes e eficazes, calcadas em preceitos de organizações privadas, reconhecendo que as organizações públicas também precisam reinterpretar sua relação com seu corpo social (PEREIRA, 1996).

Ao fazer uma análise das carreiras, Chanlat (1995) as classificou em dois modelos distintos: o tradicional e o moderno ou proteano. 0 modelo tradicional, que teve sua hegemonia até meados dos anos de 1970, é marcado pela estabilidade do emprego e a progressão se dá de forma linear vertical, reforçando grupos socialmente dominantes, notadamente na administração pública. 0 segundo modelo, de forma antagônica, pertence a um contexto de instabilidade, progressão horizontal e vertical descontínua e se apresenta de forma generalizada em diversas carreiras, com destaque para o setor privado, mas também se apresenta no setor público. $O$ contexto é o componente diferenciador, pois enquanto a sociedade que proporciona o modelo tradicional de carreira visa o enriquecimento, divisão sexual no trabalho e progresso, o modelo moderno está intimamente relacionado à inserção das minorias e mulheres no mercado de trabalho, democratização da educação e experiência em várias organizações ao longo da carreira profissional.

Utilizando-se da aplicação do modelo proposto por Schein, Faro (2007), no contexto do Tribunal de Contas da União, aos servidores de nível superior dessa instituição, teve como resultados: a inclinação daqueles atores para pouca ambição; baixo vigor; e baixa competitividade, em termos da relação com outros servidores, predominando a segurança e a estabilidade. Em suma, os resultados mostraram-se bem diferentes do preconizado pelo modelo moderno ou proteano. 


\section{A INFLUÊNCIA DAS ÂNCORAS DE CARREIRA NA SATISFAÇÃO NO TRABALHO PARA OS SERVIDORES DO TRIBUNAL DE CONTAS DO ESTADO DO MARANHÃO}

Cantarelli, Estivalete e Andrade (2014), observando os servidores técnico-administrativos em educação, encontraram as âncoras mais valorizadas como vontade de servir, dedicação a uma causa, estilo de vida e segurança e estabilidade, tendo um diferencial significante que foi a constatação da obrigação em permanecer, como elemento preponderante.

Ampliam essa visão Da Silva, Balassiano e Da Silva (2014), em trabalho qualitativo, quando afirmam haver a manifestação do burocrata alpinista, que, apesar de estável, seria um servidor que estaria interessado no seu crescimento pessoal, aperfeiçoando-se para melhoria da qualidade do serviço público, buscando, individualmente a ascensão da carreira. Um caráter mais utilitário rege suas carreiras, sendo capazes inclusive de reconstruir suas carreiras até fora do âmbito público, desde que isso seja mais útil aos seus propósitos individuais.

Apesar de estudos citados abordarem as âncoras de carreira no setor público, não foram encontrados estudos que as relacionassem positiva ou negativamente, no setor público, à satisfação no trabalho, sendo esta a contribuição deste estudo.

Ademais, há evidências que indicam uma incompatibilidade entre as reais necessidades do servidor, desejoso de construção de uma carreira, e as recompensas da organização pública, que resultam na estagnação da carreira, resistência à mudança, pouca inovação, busca exagerada por salários e benefícios e, sobretudo, a segurança (VAN DAM, 2004), impactando a satisfação no trabalho. Assim, o objetivo deste estudo foi o de investigar as âncoras de carreira relativas ao servidor público e sua relação com a satisfação no trabalho.

\section{REFERENCIAL TEÓRICO}

\subsection{Satisfação no Trabalho}

Muitos são os estudos sobre satisfação no trabalho e diversas as variáveis que a impactam. Price e Mueller (1986) afirmam que, desde os anos de 1940, tais pesquisas foram ganhando corpo, produzindo estudos tanto qualitativos quanto quantitativos.

A satisfação e a insatisfação no trabalho têm natureza emocional, identificadas, respectivamente, como alegria e sofrimento (LOCKE, 1969). Ocorrem quando, efetivamente, o sujeito, avaliando o valor do objeto, por meio do conhecimento, denota a emoção correspondente. Dá-se, portanto, ao indivíduo, uma experiência prazerosa ou não (SIQUEIRA, 2008).

O comportamento no trabalho, sobretudo na conotação da motivação, ocorre com base em dois fatores: o higiênico, quando relativo ao aspecto exterior do indivíduo, proporcionado por políticas organizacionais; e o intrínseco ou subjetivo, esse tocando diretamente a satisfação no trabalho, a realização, o reconhecimento e a possibilidade de crescimento (HERZBERG, 1968). 
Por conseguinte, de forma condensada, duas teorias abordam a satisfação no trabalho: a de cunho unidimensional e a multifatorial (TAMAYO, 2000). A primeira se baseia apenas na sua concepção emocional. A segunda reconhece a relação de diversos elementos que fomentam a satisfação, ou seja, implica no relacionamento entre o afeto do empregado, 0 ambiente e a sua atitude (BRIEF; WEISS, 2002; MARTINS; SANTOS, 2006; SPECTOR et al, 2007), podendo impactar diretamente na permanência do colaborador na organização (PRICE; MUELLER, 1986). Tamayo (2000) ressalta fatores como: condições de trabalho, benefícios, promoção, relação com os colegas, salário, estabilidade no trabalho, desenvolvimento pessoal e natureza do trabalho entre outros.

Como consequência da satisfação, os funcionários têm uma tendência maior a trabalhar com mais afinco, serem mais cooperativos com os colegas, além de exprimirem uma imagem mais positiva da organização onde trabalham. (ROBBINS et al., 2013).

Price e Mueller (1986) levaram em conta como o funcionário se sente, satisfeito ou não, em relação à organização em que trabalha, utilizando como variáveis situacionais: autonomia; rotinização; e coesão do grupo. A partir do responsivo emocional, se negativo ou positivo, se feliz ou desconfortável, confirmaram que havia uma relação determinante entre resultados, que indicaram que os funcionários são capazes de perceber a satisfação com seu trabalho na medida em que são tocados de modo afetivo, positivamente (por felicidade) ou negativamente (por desconforto).

Assim, para aferir a satisfação no trabalho, este estudo utilizou a escala desenvolvida e validada por Price e Mueller (1986), que consideram emoções negativas (o tédio e vontade de sair) em contraposição às emoções positivas (o entusiasmo, a alegria e como as demais pessoas veem o trabalho, comparando-se a terceiros) como elementos que indicam a satisfação no trabalho.

\section{2 Âncoras de Carreiras}

A compreensão de carreira envolve, mesmo na pós-modernidade, momento de grandes incertezas, a límpida percepção entre os processos objetivos e subjetivos, entre as estruturas, suas tensões e ambivalências, e o ideário individual. (EVETTS, 1992). Assim, seria o sucesso psicológico individual personificado pela realização pessoal e o orgulho 0 fim principal de toda carreira, em contraposição à mera ascensão hierárquica. (HALL, 1986).

Não obstante, Schein (1978) estabeleceu o conceito de âncoras na carreira quando verificou, por meio de estudo qualitativo longitudinal, quais são as autopercepções de necessidades, motivos e competências (habilidades e talentos), tanto das atividades que os empregados já haviam desempenhado em suas carreiras, quanto as que estavam desempenhando e as que desejavam desempenhar. 


\section{A INFLUÊNCIA DAS ÂNCORAS DE CARREIRA NA SATISFAÇÃO NO TRABALHO PARA OS SERVIDORES DO TRIBUNAL DE CONTAS DO ESTADO DO MARANHÃO}

Posteriormente, revisando as âncoras de carreira no século XXI, Schein (1996) dividiu em três dimensões a sua abordagem, considerando o que poderia influenciar diretamente as decisões sobre a carreira, ou seja, os momentos de maiores pressões que têm influência direta na escolha e manutenção da carreira: idade (ciclo biossocial), ciclo familiar e ciclo profissional. A partir de tal estudo, foram desenvolvidos oito construtos, ou âncoras de carreira, que sinalizam a autopercepção quanto à escolha de carreira e, consequentemente, a satisfação no trabalho, resumidas a seguir:

a) Competência técnica e funcional (CT): Existe quando o sujeito se destaca em uma atividade, quando tem uma notória expertise em determinada ação na organização. Assim, a sua ambição gerencial é ser um gerente técnico na área de especialização;

b) Competência administrativa geral (CG): Diz respeito ao gerenciamento do trabalho dos outros empregados, de modo coerente e coordenado. Há maior realização em seu trabalho, quando for capaz de integrar e gerenciar o esforço dos outros;

c) Segurança e estabilidade (SE): É uma âncora que se coaduna com a estabilidade financeira e no emprego, quando há continuidade na carreira e o empregado evita riscos para si;

d) Autonomia e independência (Al): O olhar foca a capacidade de trabalho sem regras ou restrições, em uma atuação com o máximo de liberdade ou de autogestão;

e) Criatividade empreendedora (CE): Evidencia o desejo de iniciar um novo negócio, sobretudo baseado em suas próprias ideias;

f) Dedicação a uma causa (SD): É avaliado o desejo de que a carreira contribua para o coletivo, permitindo uma sociedade mais justa e igualitária. Essa âncora implica sentir-se bem na carreira apenas quando há a sensação de ter feito uma contribuição real para o bem da sociedade;

g) Desafio puro (DP): Mensura o quanto o profissional gostaria de ser estimulado a resolver problemas desafiadores, quando as suas habilidades competitivas estão presentes;

h) Estilo de vida (EV): Consiste na perfeita integração entre a vida doméstica e as atividades nas organizações, entre a vida pessoal e a vida profissional.

É relevante destacar que as âncoras de carreira contribuem para a institucionalização do trabalho. Conforme destacado por Bendassolli (2009), o trabalho é construído a partir da premissa dos fluxos organizativos, ao invés da empregabilidade. Dessa forma, considerando flexibilização, novos formatos e maior interatividade, que dinamizaram as relações sociais e trabalhistas, o conceito de carreira foi ampliado por esse autor, passando de um enfoque eminentemente individual para contextos sociais e organizacionais, numa expansão da visão de Chanlat (1995) com seus modelos tradicional e moderno ou proteano. A partir da percepção do sujeito, Bendassolli (2009), por exemplo, identificou 8 
(oito) modelos emergentes de carreira: sem fronteiras, proteana, artesanal, portfólio, multidirecional, transacional, narrativa e construcionista.

\section{METODOLOGIA}

A presente pesquisa, determinada a entender a relação entre as âncoras de carreira e a satisfação no trabalho, foi descritiva quanto aos fins, quantitativa segundo sua natureza, de corte transversal e baseada em dados primários.

A unidade de análise foram os funcionários do Tribunal de Contas do Estado do Maranhão (TCE/MA). Tal escolha é justificada por ser um órgão público empenhado na gestão de pessoas, tendo um plano de cargos, carreira e salários implantado desde 2004, e por utilizar o modelo de gestão por competências desde 2010. O TCE/MA conta, atualmente, com um total de 596 funcionários, sendo 116 cargos comissionados, 329 efetivos e 137 funcionários cedidos de outros órgãos. Ressalte-se que a inclusão dos funcionários cedidos por outros órgãos não enviesa os resultados, já que o objetivo é discutir âncoras de carreira de funcionários públicos, também condição dos cedidos.

O instrumento de coleta de dados foi um questionário desenvolvido em três partes, contando com 52 itens, todas as perguntas fechadas. Inicialmente, por questão de controle, é perguntado se o respondente trabalha ou não no TCE/MA. Sendo positiva a resposta, o servidor tem acesso ao perfil sociodemográfico, com cinco questões sobre gênero, escolaridade, tempo de serviço, nível de escolaridade exigido do cargo e qual a posição funcional do respondente.

Segue-se um bloco, em forma de grade, fazendo uso da escala de concordância de Likert com cinco pontos, sendo um discordo totalmente e cinco concordo totalmente. Foram 40 afirmações sobre as âncoras de carreiras, conforme proposto por Schein (1996), sendo cinco questões para cada âncora. Por fim, há seis questões relacionadas à satisfação no trabalho, utilizando o modelo de Price e Mueller (1986).

O questionário autoaplicável foi disponibilizado no website SurveyMonkey, sendo o seu link distribuído por e-mail a todos os funcionários do TCE/MA. Antes de iniciar a pesquisa, fez-se necessário um teste-piloto com os servidores da organização em foco, para precisar o entendimento das questões. Para tanto, foram escolhidos dez servidores e não houve nenhuma necessidade de adaptação no instrumento de coleta de dados. Superada essa fase, o questionário foi disponibilizado para ser preenchido pelos demais servidores, perfazendo um total de 276 observações, o que corresponde a $46,3 \%$ da população.

Para definição da taxa de respostas, o tamanho da amostra foi determinado com base na fórmula de estimativa do Fator de Correção de População Finita. (BRUNI, 2008): 


$$
n=\frac{z^{2} p q N}{z^{2} p q+(N-1) e^{2}}
$$

Onde:

- $\mathrm{N}=$ tamanho da população

- $p=$ Quantidade de Acerto esperado $(50 \%)$

- $q=$ Quantidade de Erro esperado (50\%)

- $Z$ = transformada $Z$ para o nível de confiança desejado de $95 \%(Z=1,96)$

- $\mathrm{e}=$ Erro padrão $(5 \%)$

Assumiu-se que a população é homogênea, não havendo discrepâncias relevantes em termos de função desempenhada ou cargo ocupado. Para um intervalo de confiança de $95 \%(Z=1,96)$ e um erro de 0,5, o número mínimo de respostas seria de 234 pessoas. De acordo com Bruni (2008), quando a população analisada apresenta um tamanho finito, é preciso relativizar o tamanho da amostra em relação ao tamanho da população. Portanto, aplicando-se o Fator de Correção de População Finita (FCPF), a amostra foi representativa da população pesquisada.

$\mathrm{Na}$ análise dos dados foram utilizadas técnicas de estatística descritiva e regressão linear múltipla.

\section{APRESENTAÇÃO E DISCUSSÃO DOS RESULTADOS}

\subsection{Dados demográficos}

A dos respondentes em termos de gênero, escolaridade, nível de escolaridade do cargo que possui, tempo de serviço na instituição e tipo de cargo que ocupam encontra-se na Tabela 1.

Observa-se que a maioria dos respondentes é do sexo masculino (59,8\%). Enquanto $64,1 \%$ da amostra possuem o cargo de nível superior, 77,6\% têm escolaridade de nível superior ou mais. Portanto, há um grupo de servidores que está exercendo atividades aquém de sua formação.

Quanto ao tempo de serviço no TCE/MA, a maioria $(51,8 \%)$ da amostra respondeu possuir mais de 15 anos de atividade naquela instituição, seguida de 22,1\% que indicaram entre 10 e 15 anos de trabalho. Somente 7\% têm menos de um ano de atividades naquele órgão público. Dessa forma, tem-se um grupo experiente.

Sobre o tipo de cargo que ocupam, os respondentes são na maioria de cargo efetivo $(51,1 \%)$, dentre os quais $12,7 \%$ ocupam cargos comissionados. Há, no entanto, um grupo maior de comissionados (18,1\%), indicando que uma parcela desse grupo não pertence ao quadro do TCE/MA. 
Tabela 1 - Caracterização da Amostra

\begin{tabular}{|c|c|c|c|}
\hline Característica & Perfil dos respondentes & Quantidade & $\%$ \\
\hline \multirow[t]{2}{*}{ Gênero } & Masculino & 165 & 59,8 \\
\hline & Feminino & 111 & 40,2 \\
\hline \multirow{5}{*}{$\begin{array}{l}\text { Relação funcional com o } \\
\text { TCE/MA }\end{array}$} & Efetivo & 141 & 51,1 \\
\hline & Efetivo / cargo comissionado & 50 & 18,1 \\
\hline & Comissionado & 35 & 12,7 \\
\hline & A disposição & 39 & 14,1 \\
\hline & A disposição com cargo comissionado & 11 & 4 \\
\hline \multirow{3}{*}{$\begin{array}{l}\text { Nível de escolaridade do } \\
\text { cargo }\end{array}$} & Nível fundamental & 8 & 2,9 \\
\hline & Nível médio & 91 & 33 \\
\hline & Nível superior & 177 & 64,1 \\
\hline \multirow[t]{5}{*}{ Tempo no órgão } & Menos de um ano & 2 & 7 \\
\hline & 1 a 5 anos & 20 & 7,2 \\
\hline & 5 a 10 anos & 50 & 18,1 \\
\hline & 10 a 15 anos & 61 & 22,1 \\
\hline & Acima de 15 anos & 143 & 51,8 \\
\hline \multirow[t]{5}{*}{ Escolaridade } & Ensino fundamental & 1 & 4 \\
\hline & Ensino médio & 52 & 18,8 \\
\hline & Ensino superior & 90 & 32,6 \\
\hline & Especialização & 121 & 43,8 \\
\hline & Mestrado & 12 & 4,3 \\
\hline
\end{tabular}

Fonte: Dados da pesquisa.

\subsection{Estatística descritiva}

A partir das respostas às variáveis que procuraram estabelecer o grau de importância dada pelos respondentes às âncoras de carreira, observaram-se médias e desvios padrão apresentados na Tabela 2.

Tabela 2 - Estatística Descritiva

\begin{tabular}{l|l|r|r}
\hline \multicolumn{1}{c|}{ Construto } & \multicolumn{1}{c|}{ Variável } & Média & \multicolumn{1}{c}{$\begin{array}{c}\text { Desvio } \\
\text { Padrão }\end{array}$} \\
\hline $\begin{array}{l}\text { Competência } \\
\text { Técnica/ }\end{array}$ & $\begin{array}{l}\text { Sonho ser tão bom no que faço, de tal forma que meus } \\
\text { conhecimentos especializados sejam constantemente procurados }\end{array}$ & 4,14 & 1,00 \\
\hline
\end{tabular}




\section{A INFLUÊNCIA DAS ÂNCORAS DE CARREIRA NA SATISFAÇÃO NO TRABALHO PARA OS SERVIDORES DO TRIBUNAL DE CONTAS DO ESTADO DO MARANHÃO}

Funcional (CT) S Sinto-me bem-sucedido em minha carreira apenas quando posso desenvolver minhas habilidades técnicas ou funcionais a um nível de competência muito alto

Tornar-me um gerente técnico em minha área de especialização é mais atraente para mim do que tornar-me um gerente geral. Preferiria deixar meu emprego do que aceitar uma tarefa de rodízio que me afaste da minha área de experiência Me sinto plenamente realizado em meu trabalho quando sou capaz de empregar minhas habilidades e talentos especiais Competência Técnica/Funcional

abalho quando sou capaz de

Sinto-me mais realizado em meu trabalho quando sou capaz de integrar e gerenciar o esforço dos outros Sonho em dirigir uma organização complexa e tomar decisões que afetem muitas pessoas

\begin{tabular}{l|l|l}
\hline ação é & 3,36 & 1,30 \\
\hline & 2,55 & 1,34 \\
\hline & 4,30 & 0,90 \\
\hline
\end{tabular}

Competência Administrativa Sentir-me-ei bem-sucedido em minha carreira apenas quando me Geral (CA) tornar um gerente geral de alguma organização Tornar-me um gerente geral é mais atraente para mim do que tornar-me um gerente técnico em minha área de especialização. Prefiro sair da minha organização a aceitar um cargo que me afaste do caminho da gerência geral

Competência Administrativa Geral

Sonho em ter uma carreira que me dê a liberdade de fazer 0 trabalho à minha maneira e no tempo por mim programado Sinto-me mais realizado em meu trabalho quando tenho total liberdade de definir minhas próprias tarefas, horários e 3,55 0,67 procedimentos

Autonomia e Independência (Al) Sentir-me-ei bem-sucedido em minha carreira apenas quando alcançar total autonomia e liberdade

\begin{tabular}{|l|l|}
\hline 3,55 & $\mathbf{0 , 6 7}$ \\
\hline 4,04 & 1,13 \\
\hline 2,79 & 1,47 \\
\hline
\end{tabular}

Para mim, poder fazer um trabalho do meu jeito, livre de regras e restrições, é mais importante que segurança Preferia deixar a minha organização do que aceitar um emprego que reduza minha autonomia e liberdade

Autonomia e Independência

Segurança e estabilidade são mais importantes pra mim do que liberdade e autonomia Preferiria deixar meu emprego do que aceitar uma tarefa que possa colocar em risco minha segurança na instituição

Segurança e Estabilidade (SE) Procuro trabalhos em organizações que me deem senso de segurança e estabilidade

Sinto-me realizado em meu trabalho quando percebo que tenho total segurança e estabilidade no trabalho Sonho em ter uma carreira que me dê senso de segurança e estabilidade

Segurança e Estabilidade

2,17

2,17 1,25

.

2,41

2,26

\begin{tabular}{|l|l|}
\hline $\mathbf{2 , 7 3}$ & $\mathbf{0 , 8 2}$ \\
\hline 3,93 & 1,18 \\
\hline 3,77 & 1,22 \\
\hline
\end{tabular}


(continuação)

\begin{tabular}{|c|c|c|c|}
\hline Construto & Variável & Média & $\begin{array}{l}\text { Desvio } \\
\text { Padrão }\end{array}$ \\
\hline \multirow{6}{*}{$\begin{array}{l}\text { Criatividade } \\
\text { Empreendedora } \\
\text { (CE) }\end{array}$} & $\begin{array}{l}\text { Estou sempre procurando ideias que me permitam iniciar meu próprio } \\
\text { negócio }\end{array}$ & 3,07 & 1,43 \\
\hline & $\begin{array}{l}\text { Montar meu próprio negócio é mais importante para mim do que atingir } \\
\text { uma alta posição gerencial como empregado }\end{array}$ & 2,51 & 1,40 \\
\hline & $\begin{array}{l}\text { Sinto-me realizado em minha carreira quando há oportunidade de } \\
\text { construir alguma coisa que seja resultado unicamente de minhas } \\
\text { próprias ideias e esforços }\end{array}$ & 3,07 & 1,39 \\
\hline & $\begin{array}{l}\text { Sinto-me bem-sucedido no trabalho apenas quando posso criar ou } \\
\text { construir alguma coisa que seja inteiramente de minha autoria }\end{array}$ & 2,67 & 1,48 \\
\hline & Sonho em iniciar e montar meu próprio negócio & 3,00 & 1,46 \\
\hline & Criatividade Empreendedora & 2,86 & 0,95 \\
\hline \multirow{6}{*}{$\begin{array}{l}\text { Dedicação a uma } \\
\text { Causa (DC) }\end{array}$} & $\begin{array}{l}\text { Sinto-me bem em minha carreira apenas quando tenho a sensação de } \\
\text { ter feito uma contribuição real para o bem da sociedade }\end{array}$ & 4,01 & 1,12 \\
\hline & $\begin{array}{l}\text { Sinto-me mais realizado em minha carreira quando posso utilizar meus } \\
\text { talentos a serviço dos outros }\end{array}$ & 4,17 & 0,96 \\
\hline & $\begin{array}{l}\text { Utilizar minhas habilidades para tornar o mundo um lugar melhor para se } \\
\text { viver e trabalhar, é mais importante para mim do que alcançar uma } \\
\text { posição gerencial de alto nível }\end{array}$ & 3,97 & 1,18 \\
\hline & $\begin{array}{l}\text { Sonho em ter uma carreira que faça uma real contribuição à humanidade } \\
\text { e à sociedade }\end{array}$ & 4,40 & 0,88 \\
\hline & $\begin{array}{l}\text { Prefiro sair da organização onde estou a aceitar uma tarefa que } \\
\text { prejudique minha capacidade de servir aos outros }\end{array}$ & 3,25 & 1,33 \\
\hline & Dedicação a uma Causa & 3,96 & 0,70 \\
\hline \multirow{6}{*}{ Desafio Puro (DP) } & $\begin{array}{l}\text { Sonho com uma carreira na qual eu possa solucionar problemas ou } \\
\text { vencer com situações extremamente desafiadoras }\end{array}$ & 4,04 & 0,98 \\
\hline & $\begin{array}{l}\text { Sinto-me realizado em minha carreira apenas quando enfrento e supero } \\
\text { desafios extremamente difíceis }\end{array}$ & 3,34 & 1,30 \\
\hline & $\begin{array}{l}\text { Sinto-me mais realizado em minha carreira quando solucionei problemas } \\
\text { insolúveis ou venci o que aparentemente era impossivel de ser vencido. }\end{array}$ & 4,01 & 1,09 \\
\hline & $\begin{array}{l}\text { Procuro oportunidades de trabalho que desafiem fortemente minhas } \\
\text { habilidades para solucionar problemas }\end{array}$ & 3,96 & 1,04 \\
\hline & $\begin{array}{l}\text { Trabalhar em problemas praticamente insolúveis é mais importante do } \\
\text { que alcançar uma posição gerencial de alto nível. }\end{array}$ & 2,93 & 1,27 \\
\hline & Desafio Puro & 3,66 & 0,77 \\
\hline \multirow{6}{*}{ Estilo de Vida (EV) } & $\begin{array}{l}\text { Preferiria deixar meu emprego do que ser colocado em um trabalho que } \\
\text { comprometa minha capacidade de me dedicar aos assuntos pessoais e } \\
\text { familiares }\end{array}$ & 3,24 & 1,38 \\
\hline & $\begin{array}{l}\text { Sonho com uma carreira que me permita integrar minhas necessidades } \\
\text { pessoais, familiares e de trabalho. }\end{array}$ & 4,30 & 1,00 \\
\hline & $\begin{array}{l}\text { Sinto-me bem-sucedido na vida apenas quando fui capaz de equilibrar } \\
\text { minhas necessidades pessoais, familiares e de carreira. }\end{array}$ & 3,78 & 1,17 \\
\hline & $\begin{array}{l}\text { Equilibrar as exigências da minha vida pessoal e profissional é mais } \\
\text { importante do que alcançar alta posição gerencial }\end{array}$ & 4,06 & 1,08 \\
\hline & $\begin{array}{l}\text { Sempre procurei oportunidades de trabalho que minimizassem } \\
\text { interferências com assuntos pessoais e familiares }\end{array}$ & 3,58 & 1,20 \\
\hline & Estilo de Vida & 3,79 & 0,68 \\
\hline
\end{tabular}

(continua) 
A INFLUÊNCIA DAS ÂNCORAS DE CARREIRA NA SATISFAÇÃO NO TRABALHO PARA OS SERVIDORES DO TRIBUNAL DE CONTAS DO ESTADO DO MARANHÃO

(continuação)

\begin{tabular}{|c|c|c|c|}
\hline Construto & Variável & Média & $\begin{array}{l}\text { Desvio } \\
\text { Padrão }\end{array}$ \\
\hline \multirow{7}{*}{$\begin{array}{l}\text { Satisfação no } \\
\text { Trabalho (ST) }\end{array}$} & Eu encontro alegria real no meu trabalho & 4.05 & 1,07 \\
\hline & $\begin{array}{l}\text { Eu gosto mais do meu trabalho do que as pessoas em geral gostam do } \\
\text { trabalho delas }\end{array}$ & 3,41 & 1,10 \\
\hline & Raramente eu fico entediado com o meu trabalho & 2,08 & 1,25 \\
\hline & Eu não levaria em consideração uma troca de emprego & 2,99 & 1,42 \\
\hline & Na maioria dos dias, eu estou entusiasmado com o meu trabalho & 3,91 & 1,05 \\
\hline & Eu me sinto bem satisfeito com o meu trabalho & 4,10 & 1,03 \\
\hline & Satisfação no Trabalho & 3,42 & 0,60 \\
\hline
\end{tabular}

Fonte: Dados da pesquisa.

Evidencia-se que os respondentes tendem a concordar com as afirmações que suportam os construtos Competência Técnica/Funcional (CT), Segurança e Estabilidade (SE), Dedicação a uma Causa (DC), Desafio Puro (DP) e Estilo de Vida (EV); portanto, estas seriam dimensões importantes para suas carreiras. Nos demais - Competência Administrativa Geral (CA), Autonomia e Independência (AI) e Criatividade Empreendedora (CE) - há uma tendência à indiferença, permitindo avaliar que tais construtos são neutros para fins de suas carreiras na população estudada. As percepções dessas últimas, orientadas ao comando, liberdade e proatividade, contrárias às primeiras, vão ao encontro do estudo de Faro (2007), realizado no Tribunal de Contas da União, que enfatizou a inclinação daqueles atores para pouca ambição; baixo vigor; e baixa competitividade, em termos da relação com outros servidores, predominando a segurança e a estabilidade.

Percebe-se que a maior média $(M=3,96)$, ou seja, a maior tendência à concordância tem um menor grau de dispersão ( $D P=0,70$ ) e refere-se ao construto $D C$ (Dedicação a um Causa). Isso aponta uma homogeneidade na opinião da amostra, o que permite inferir que a escolha da carreira no TCE/MA busca o reconhecimento de que suas atividades contribuem para tornar o mundo um local melhor. Ao analisar o controle externo, atividade principal daquele órgão, há justamente um foco para que os recursos públicos sejam usados de modo mais efetivo para a sociedade. O que se nota é que os servidores respondentes da pesquisa esperam que suas carreiras tenham esse impacto, alinhado ao resultado do trabalho de Cantarelli, Estivalete e Andrade (2014).

Analisando as dez afirmações de maiores pontuações, predomina o construto Dedicação a uma Causa, com três questões, seguida de Competência Técnica/Funcional, Estilo de Vida (EV) e Desafio Puro, estes com duas questões de altas médias, ou seja, com médias superiores a quatro, indicando concordância. Todas são situações que valorizam a carreira em virtude de sua especialidade e importância para a sociedade, mostrando que os servidores têm a tendência a valorizar suas carreiras pela utilidade delas para a sociedade, congregando esses interesses com os seus interesses pessoais e familiares. 
Em outra perspectiva, analisando as dez questões com menores pontuações, percebe-se a predominância das âncoras da Competência Administrativa Gerencial e da Criatividade Empreendedora, em que seis afirmações tendem à não concordância. Portanto, o servidor tende a: possuir pouca predisposição por sair da organização em prol de novos empreendimentos; afastar qualquer ímpeto empreendedor ou de se tornar empresário; reforçar o ideário de estabilização na carreira; e não se sensibilizar pela busca de carreiras que tenham algum risco envolvido. Ainda, depreende-se que o servidor desvaloriza a liderança, elemento implícito em ambas as âncoras de carreira.

Analisando a variável Competência Administrativa Geral $(M=2,73)$, portanto abaixo da linha da neutralidade, tendendo à não concordância, nota-se um baixo valor de dispersão $(D P=0,82)$, apontando para uma homogeneidade de percepções. Isso pode ter ocorrido porque havia pessoas na amostra que preenchiam cargos de chefia geral, assim se posicionando com valores mais baixos. De modo geral, salienta-se que uma das variáveis (relativa à capacidade de integrar e gerenciar esforço dos outros) obteve alta média, indicando concordância, embora com alta dispersão. Logo, permite inferir que o servidor se importa com o trabalho de gestão que beneficia sua equipe, mas não tem interesse em desenvolver uma carreira que o leve a uma posição de comando geral e a atividades administrativas.

\subsection{Regressão linear múltipla}

Para verificar a relação dos 8 (oito) construtos com a variável dependente Satisfação no Trabalho, foi utilizada a regressão linear múltipla, cujos resultados encontram-se nas Tabelas 3 e 4.

O coeficiente múltiplo de regressão $\left(R^{2}\right)$ ajustado mostra que as variáveis significativas de âncoras de carreira explicam 19,4\% da Satisfação no Trabalho, o que adverte que há outras dimensões não consideradas no estudo. A heterocedasticidade e o teste de normalidade apresentaram resultados aceitáveis.

Ao analisar os modelos de regressão com todas as variáveis independentes pelo método stepwise, foi obtido um modelo com três construtos significantes para um intervalo de confiança de 99\%: SE - Segurança e Estabilidade, CA - Competência Administrativa Geral; e CT - Competência Técnica/Funcional.

Os construtos SE e CT mostram-se proporcionalmente associados de forma positiva à Satisfação no Trabalho. Por outro lado, a CA está associada de forma inversamente proporcional à variável dependente, ou seja, quanto maior for a Competência Administrativa Geral relacionada à posição do servidor em sua carreira, menor será sua Satisfação no Trabalho. 


\begin{tabular}{|c|c|c|c|c|c|c|c|c|c|c|}
\hline \multirow[b]{2}{*}{ Modelo } & \multirow[b]{2}{*}{$\mathrm{R}$} & \multirow[b]{2}{*}{$\mathrm{R}^{2}$} & \multirow[b]{2}{*}{$\begin{array}{c}\mathrm{R}^{2} \\
\text { ajustado }\end{array}$} & \multirow[b]{2}{*}{$\begin{array}{l}\text { Erro padrão } \\
\text { da estimativa }\end{array}$} & \multicolumn{5}{|c|}{ Alterações Estatísticas } & \multirow[b]{2}{*}{ Durbin-Watson } \\
\hline & & & & & $\begin{array}{c}\text { Variação } \\
\text { do } R^{2}\end{array}$ & $\mathrm{~F}$ & \begin{tabular}{c|}
$d f$ \\
1
\end{tabular} & df2 & $\begin{array}{c}\text { Alterações } \\
\text { Sig. F }\end{array}$ & \\
\hline 3 & $450^{\circ}$ & 203 & ,194 & ,53843 & 019 & 6,449 & & 72 & 012 & 0,927 \\
\hline
\end{tabular}

Fonte: Dados da pesquisa.

Observação: a. Preditores: (Constante), SE, CA, CT

b. Variável Dependente: ST

Método de estimação: Stepwise

Testes de validez:

-ANOVA: significativo

- Teste de Aleatoriedade: aceita a hipótese de aleatoriedade

- Teste de Aderência Kolmogorov-Smirnov: aceita hipótese de aderência à distribuição nomal

- Teste de Homocedasticidade: aceita a hipótese de homocedasticidade

Tabela 4 - Coeficientes Estimados da Variável Dependente "Satisfação no Trabalho"

\begin{tabular}{|c|c|c|c|c|c|c|c|c|c|c|c|c|}
\hline \multirow{2}{*}{ Variáveis } & \multicolumn{2}{|c|}{$\begin{array}{l}\text { Coeficientes não } \\
\text { padronizados }\end{array}$} & \multirow{2}{*}{$\begin{array}{c}\begin{array}{c}\text { Coef. } \\
\text { padron. }\end{array} \\
\text { Beta }\end{array}$} & \multirow{2}{*}{$T$} & \multirow{2}{*}{ Sig. } & \multicolumn{2}{|c|}{$\begin{array}{c}95,0 \% \text { Interv. } \\
\text { de Conf. para } \\
\text { B }\end{array}$} & \multicolumn{3}{|c|}{ Correlação } & \multicolumn{2}{|c|}{$\begin{array}{l}\text { Estatísticas de } \\
\text { colinearidade }\end{array}$} \\
\hline & B & $\begin{array}{c}\text { Erro } \\
\text { Padrão }\end{array}$ & & & & $\begin{array}{c}\text { Limite } \\
\text { Inf. } \\
\end{array}$ & $\begin{array}{l}\text { Limite } \\
\text { Sup. }\end{array}$ & $\begin{array}{c}\text { Ordem } \\
\text { Zero }\end{array}$ & Parcial & Part. & Toler. & VIF \\
\hline (Const.) & 2,068 &, 217 & & 9,530 & ,000 & 1,641 & 2,496 & & & & & \\
\hline SE & ,322 & , 050 & ,378 & 6,464 &, 000 & ,224 &, 419 & ,404 & ,365 & ,350 & ,957 & 1,116 \\
\hline $\mathrm{CA}$ &,- 161 & ,045 &,- 221 & $-3,546$ &, 000 &,- 250 &,- 072 &,- 073 &,- 210 &,- 192 & ,757 & 1,320 \\
\hline CT & ,150 & ,059 & ,168 & 2,540 & ,012 & ,034 & ,267 & ,202 & ,152 & ,137 & ,669 & 1,494 \\
\hline
\end{tabular}

Fonte: Dados da pesquisa.

Observação: Variável Dependente: Satisfação no trabalho (ST)

SE- Segurança e estabilidade;

CA - Competência administrativa geral

$\mathrm{CT}$ - Competência técnica/funcional

A partir desses dados, verifica-se que, para o servidor da instituição pesquisada, a segurança e a estabilidade são elementos que lhe proporcionam satisfação no trabalho, o que é compatível com a opção por uma carreira no serviço público. Isso não significa que carreiras nesse contexto não devam ser gerenciadas, conforme Hayek (1987). Soma-se a isso o desenvolvimento da competência técnica. Sendo assim, o servidor associa sua satisfação no trabalho a elementos diretamente relacionados a um modelo de gestão ancorado na estabilidade e na especialização, característica de modelos burocráticos tradicionais.

Por outro lado, há um efeito inversamente proporcional entre satisfação e competência administrativa geral, o que indica aversão ao trabalho em atividades administrativas, de suporte ou de liderança, e não finalísticas. No caso do Brasil, esse resultado pode estar relacionado a um possível inchaço da máquina burocrática, de forma a acomodar forças políticas.

Meiliani (2014) já afirmava que estabilidade é um atrativo para quem quer seguir a carreira pública, o que está alinhado com o resultado de diversas outras pesquisas (FARIA; SILVEIRA, 2015; FARO, 2007; PACHECO, 2011). A presença da competitividade é um elemento diferenciador entre a gestão pública e a gestão privada (PINHEIRO; SAVOIA; ANGELO, 2016). Faro (2007) e Da Silva, 
Balassiano e Da Silva (2014) já apontavam a baixa ambição para cargos que demandam competências gerenciais gerais.

Pacheco (2011) ratifica os resultados ao afirmar que, por ausência de autonomia e flexibilidade da administração pública, há certa indiferença aos incentivos econômicos e à competição, comuns no ambiente empresarial, explicando, assim, os resultados da pesquisa sobre o efeito negativo da âncora da competência administrativa geral sobre a satisfação no trabalho.

\section{CONCLUSÃO}

O objetivo desta pesquisa foi o de identificar as âncoras de carreira e relacioná-las com a satisfação no trabalho, utilizando, especificamente, uma amostra de servidores públicos do Tribunal de Contas do Estado do Maranhão. Os resultados sugeriram que há relação significante positiva entre as âncoras de carreira de segurança e estabilidade (SE) e competência técnica/funcional (CT) com a satisfação no trabalho. Entretanto, embora significante, a âncora da Competência Administrativa Geral (CA) está inversamente proporcional à satisfação no trabalho. Isso permite considerar que os servidores não têm expectativas quanto às competências requeridas e à execução de atividades administrativas, diminuindo, nesses casos, sua satisfação com o trabalho.

As demais âncoras de carreira pesquisadas não foram significantes para a satisfação no trabalho. No caso de autonomia e independência ( $\mathrm{Al}$ ) e criatividade empreendedora (CE) a análise estatística descritiva já apontava para uma tendência à indiferença. No entanto, as âncoras de dedicação a uma causa (DC), desafio puro (DP) e estilo de vida (EV) obtiveram uma acolhida, tendendo à concordância no conjunto das variáveis utilizadas para a apuração de percepções. Ainda assim, não foram significantes, quando da regressão múltipla, para explicação da satisfação no trabalho.

Tais resultados podem ajudar a administração pública a reavaliar suas políticas de gestão de pessoas para preenchimento de cargos, especialmente os de chefias, e incentivo meritório para acesso a esses cargos, incorporando a novos elementos que desenvolvam habilidades e competências na gestão de pessoas.

Destaque-se que $70 \%$ dos respondentes afirmaram possuir mais de 10 anos de serviço público, portanto já relativamente consolidados em suas carreiras. Apesar de desejarem e valorizarem a segurança e a estabilidade, gostam de situações desafiadoras que envolvam criatividade, e têm consciência de que sua atuação afeta diretamente a sociedade.

O estudo apresentou limitações. No que concerne à amostra, restringiu-se a uma única instituição pública, logo, os resultados não são passíveis de generalizações. Outro ponto a destacar foi a utilização de apenas uma escala de satisfação no trabalho, de caráter unidimensional, que não 
abordou, por exemplo, fatores higiênicos, o que poderia levar a outras considerações relevantes. 0 modelo utilizado explicou $19,4 \%$ da satisfação no trabalho, o que abre caminhos para pesquisas com outros construtos que indiquem âncoras de carreira, como, por exemplo, a remuneração e estrutura hierárquica, além de outras dimensões não ligadas diretamente às carreiras, mas que sensibilizem a satisfação no trabalho.

Sugerem-se, também, futuros estudos de natureza qualitativa e que sejam extensivos a outros órgãos públicos, em outras localidades, com diferentes ambientes sociais e políticos.

\section{REFERÊNCIAS}

BENDASSOLLI, P. F. Recomposição da relação sujeito-trabalho nos modelos emergentes de carreira. RAE-Revista de Administração de Empresas, São Paulo, v. 49, n. 4, p. 387-400, 2009.

BRIEF, A. P.; WEISS, H. M. Organizational behavior: Affect in the workplace. Annual Review of Psychology, [S. I.], v. 53, n. 1, p. 279-307, 2002.

BRUNI, A. L. Estatística Aplicada à Gestão Empresarial. 2. ed. São Paulo: Atlas, 2008.

CANTARELLI, N. M.; ESTIVALETE, V. F. B.; ANDRADE, T. Âncoras de carreira e comprometimento organizacional: ampliando a sua compreensão. Base, Cristo Rei, v. 11, n. 2, p. 153-166, 2014.

CHANLAT, J.-F. Quais carreiras e para qual sociedade? Revista de Administração de Empresas, São Paulo, v. 35, n. 6, p. 67-75, 1995.

DA SILVA, J. R.; BALASSIANO, M.; DA SILVA, A. R. L. Burocrata proteano: articulações de carreira em torno e além do setor público. RAC - Revista de Administração Contemporânea, Rio de Janerio, v. 18, n. 1, p. 1-19, 2014.

DUTRA, J. S. Trajetórias de carreira nas organizações. In DUTRA, J. S. Gestão de carreiras na empresa contemporânea. São Paulo: Atlas, 2010.

EVETTS, J. Dimensions of career: avoiding reification in the analysis of change. Sociology, [S. I.], v. 26, n. 1, p. 1-21, 1992.

FARIA, E. O.; SILVEIRA, T. R. Os Fatores que influenciam os egressos do curso de secretariado executivo trilíngue da Universidade Federal De Viçosa a ingressarem no serviço público. Revista de Gestão e Secretariado, São Paulo, v. 6, n. 1, p. 48-73, 2015.

FARO, E. S. C. Âncoras de carreira e o modelo de administração gerencial: um estudo de caso do Tribunal de Contas da União. 2007. Dissertação (Mestrado em Administração) - Pontifícia Universidade Católica de São Paulo, São Paulo, 2007.

HALL, D. T. Career development in organizations. San Francisco: Jossey-Bass Inc Pub, 1986.

HAYEK, F. O caminho da servidão. 4.ed. Rio de Janeiro: Instituto Liberal, 1987. 
HERZBERG, F. One more time: How do you motivate employees. Boston: Harvard Business Review, 1968.

LOCKE, E. A. What is job satisfaction? Organizational Behaviour Human Performance, [S. I.], v. 4, n. 4, p. 309-336, 1969.

MARTINS, M. C. F.; SANTOS, G. E. Adaptação e validação de construto da escala de satisfação no trabalho. Psico, Bragança Paulista, v. 11, n. 2, p. 195-205, 2006.

MEILIANI, M. Career anchors and job satisfaction: the role of psychological empowerment in the Indonesian public university context. Australia: University of Wollongong, 2014.

PACHECO, R. S. Critérios de nomeação para cargos de direção no setor público. Desigualdade e Diversidade - Revista de Ciências Sociais, Rio de Janerio, ed. esp., p. 21-30, 2011.

PEREIRA, L. C. B. Da administração pública burocrática à gerencial. Revista do Serviço Público, Brasília, DF, v. 47, n. 1, p. 7-40, 1996.

PINHEIRO, F. A. P.; SAVOIA, J. R. F.; DE ANGELO, C. F. Análise Comparativa da Atuação de Prestadores de Serviços de Saneamento Públicos e Privados no Brasil. Brazilian Business Review, Boa vista, v. 13, n. 1, p. 118-140, 2016.

PRICE, J. L.; MUELLER, C. W. Absenteeism and turnover of hospital employees. Greenwich: JAI Press, 1986.

ROBBINS, S. et al.Organisational behaviour. Australia: Pearson Higher Education, 2013.

SCHEIN, E. H. Career anchors revisited: Implications for career development in the $21^{\text {st }}$ century. The Academy of Management Executive, [S. I.], v. 10, n. 4, p. 80-88, 1996.

SCHEIN, E. H. Career dynamics: matching individual and organizational needs. Reading, MA: Addison-Wesley, 1978.

SIQUEIRA, M. M. M. Satisfação no trabalho. In SIQUEIRA, M. M. M. (ed.). Medidas do Comportamento Organizacional. Porto Alegre: Artmed, 2008. p. 265-274.

SPECTOR, P. E. et al. Cross-national differences in relationships in of work demands, job satisfaction, and turnover intentions with work-family conflict. Personnel Psychology, [S. I.], v. 60, n. 4, p. 805-835, 2007.

TAMAYO, A. Prioridades axiológicas e satisfação no trabalho. Revista de Administração, São Paulo, v. 35 , n. 2, p. 37-47, 2000.

ULRICH; D.; ULRICH, W. Por quê trabalhamos? Porto Alegre: Bookman, 2011.

VAN DAM, K. Antecedents and consequences of employability orientation. European Journal of Work and Organizational Psychology, [S. I.], v. 13, n. 1, p. 29-51, 2004. 